Asian J. Med. Biol. Res. 2021, 7 (1), 82-89; doi: 10.3329/ajmbr.v7i1.53313

\author{
Asian Journal of \\ Medical and Biological Research \\ ISSN 2411-4472 (Print) 2412-5571 (Online) \\ www.ebupress.com/journal/ajmbr
}

\title{
Article \\ Lifestyle and heritability effects on cancer in Bangladesh: an application of Cox proportional hazards model
}

\author{
Mst. Farzana Akter ${ }^{1}$, Shahnaj Sultana Sathi ${ }^{1}$, Sabikunnaher Mitu ${ }^{2}$ and Mohammad Ohid Ullah*1 \\ ${ }^{1}$ Department of Statistics, Shahjalal University of Science and Technology, Sylhet-3114, Bangladesh \\ ${ }^{2}$ Department of Sociology, Shahjalal University of Science and Technology, Sylhet-3114, Bangladesh \\ *Corresponding author: Professor Dr. Mohammad Ohid Ullah, Department of Statistics, Shahjalal University of \\ Science and Technology, Sylhet-3114, Bangladesh. Phone: +8801818101435; E-mail: ohid-sta@ sust.edu
}

Received: 04 March 2021/Accepted: 29 March 2021/ Published: 31 March 2021

\begin{abstract}
The burden of cancer is increasing very rapidly day by day all over the world, largely due to an increasing unhealthy lifestyle. Some cross-sectional studies have been conducted on lifestyle of cancer patients based on Sylhet city, Bangladesh. However, to the best of our knowledge, no study has been done based on longitudinal aspect considering whole Bangladesh, therefore, we aimed to conduct a longitudinal study to know the effects of lifestyle and heritability on cancer in Bangladesh. We selected total 384 cancer patients by using simple random sampling from eight divisions during December 2018, and created a cohort in each division in Bangladesh. After one year, we collected their survival data from four selected cohorts. We used a Cox proportional hazards model for survival data. It was found that overall female patient's survival rate is higher than male patients. It was also observed that the significant factors of the lifestyle dimension influence the hazard function of the cancer patients. It indicates that more consumption of beverages, fast food, chips/chocolates/ice-cream, smoking and betel nut increased the hazard of cancer. That is, changing lifestyle is needed to reduce the cancer diseases in future. Taken together, the findings of this study may be able to make awareness in the society about the cancer, afterwards it might be able to reduce the cancer diseases in future in regional, national and international level to improve public health sectors.
\end{abstract}

Keywords: cancer; lifestyle; longitudinal study; survival data; Cox-model; Bangladesh

\begin{abstract}
1. Introduction
Cancer is main killer diseases all over the world. The burden of cancer is increasing very rapidly day by day because of increasing unhealthy lifestyle. It is a major health problem in developed country and second highest cause of death in developing countries. In 2012 about 14.1 million people were attacked by cancer in the world. Among them 8.2 million people were deaths (Hussain and Sullivan, 2013; "WHO | World Cancer Report 2014," World Health Organization, 2014; Zaman and Baki, 2009). Cancer is caused by both internal factors such as inherited mutations, hormones and immures conditions and the important lifestyle factors or environmental factors that affect the incidence and mortality of cancer include tobacco, alcohol, diet, obesity, infectious agents, environmental pollutants, and radiation(Anand et al., 2008; Argos et al., 2014; Ashrafunnessa et al., 2005; Danaei et al., 2005; Fitzgerald et al., 2010; Khatun et al., 2009; McPherson et al., 2000; Mukti et al., 2014). The contributions of genes and environmental factors towards cancer risk is (5-10) \% and (90-95) \% respectively (Hussain and Sullivan, 2013).

According to cancer registry of NICRH (2009-2015) there are 2.5 lakh cancer patients in Bangladesh while approximately 2 lakh people develop and 1.5 lakh die of the disease (Hussain and Zaman, 2008). Based on the online literature and reports we have found only five different studies (Hasan et al., 2012; Hussain, 2013; Shahriar et al., 2011; Talukder et al., 2008; Uddin et al., 2013) where researchers have been investigated status of cancer disease in Bangladesh based on Dhaka city. As the studies did not use the same reference standard, the
\end{abstract}


prevalence of cancer is varied. Studies show that males have been suffering from cancer mostly lung, stomach, colorectal, lymphoma, and oral etc. Among them most of the people have been sufferings from lung cancer. On the other hand among female, researchers have been found breast cancer is the highest one followed by carcinoma cervix, stomach, colorectal and cancer of ovary. The ratio of male and female patients is 1.4:1. According to their findings the underlying risk factors are smoking, betel leaf, obesity, HPV infection, Helicobacter pylori. Studies also show that most of the female patients are housewives and most of the male patients are agricultural workers. Most of the patients are illiterate and are in age group (30-65) years.

In 2016, Ullah et al. (2016) conducted a study based on Sylhet city to know the extent of environmental and heritability effects on cancer, we found that theextent of environmental effect (path coefficient $=0.37$ ) is more than the heritability effect (path coefficient $=0.15$ ) and it shows that higher BMI, less exercise, and taking more junk food and meat might be the more influential factors for cancer.

Many studies (Bruner et al., 2003; Coté et al., 2012; GBD 2015 Disease and Injury Incidence and Prevalence Collaborators, 2016; GBD 2015 Mortality and Causes of Death Collaborators, 2016; Global Burden of Disease Cancer Collaboration et al., 2018; Kampman, 2007; McGuire, 2016; Nelson et al., 2013; Shahriar et al., 2011; Soerjomataram et al., 2018; Sung et al., 2019; Wolinet al., 2009; Wu et al., 2013) have been conducted including status and lifestyle of cancer patients. However, none study has been conducted covering whole Bangladesh on lifestyle and heritability effects on cancer, therefore, we would like to extend the study including longitudinal concept including survival data in the perspective of Bangladesh. In this study, our primary objective is to find out the lifestyle and heritability effects on cancer in Bangladesh considering survival data using Cox proportional hazardsmodel.

\section{Materials and Methods}

To find out the extent of heritability and lifestyle (environmental) effects on cancer, a semi-structured questionnaire has been prepared to collect the data from the cancer patients. At first we selected some cancer patients randomly from each division/strata and created a cohort in each division. We collected total 384 cancer patients from the hospitals of 8 divisional cities in Bangladesh. Initially $\left(\mathrm{T}_{0}\right)$, for cross-sectional data, we collected the information (life style, food habits, height, weight and demographic variables etc. and different blood test results) from the selected patients based on a questionnaire.

\subsection{Data Sources}

We conducted a cross-sectional study during December, 2018 in Bangladesh and the study population was the cancer patients from all over Bangladesh. Bangladesh is divided into eight (8) divisions for administrative purpose and these are- Dhaka (Capital), Chattogram, Rajshahi, Sylhet, Barishal, Rangpur, Khulna, and Mymensingh. The participants were the cancer patients going to treat cancer at public/private hospitals in different divisions of Bangladesh and simple random sampling procedure was used to collect sample from the study population.

A structured questionnaire was used to collect information from the cancer patients and the questionnaire included socio-demographic information, family history of cancer, eating behavior, pathological information, therapeutic data, and costing details. Information was collected from patients who were willing to give their details and from their relatives if the patients were not in such state to answer all questions. The study was approved by the research Center of SUST, Shahjalal University of Science and Technology (SUST), Sylhet, Bangladesh. Data collection was conducted by approaching to cancer patients who were waiting to meet the oncologist at cancer unit of different hospitals or taking therapy in hospitals. At first, socio-demographic information, costing details, therapeutic data, and eating behavior were collected orally from patients. Then pathological information and measurement of human body (Height, weight before and after cancer) were collected from their medical reports file. In each division information was collected in 3-4 days from as many patients as found.

After one year (during December, 2019), we selected 4 (four) cohorts by using a simple random sampling from the total 8 (eight) divisions/cohorts and then followed the initially selected patients around 12 months. After 12 months $\left(\mathrm{T}_{12}\right)$ we collected information such as: survive( yes/no), survival time (duration of disease, that is difference between death time and detecting time of cancer), weight status (increase, stable, decrease), food habits (better, as usual, worse) from 4 divisions( Dhaka, Chattogram Sylhet and Mymensingh). For the Cox model we used gender, factors of lifestyle and heritability dimensions. Factors of lifestyle and heritability dimensions have been selected by Principal component analysis (PCA) separately.

For data entry, processing and analysis we used Statistical Package for Social Sciences (SPSS) version 22.0. Exploratory data analysis, PCA and Cox proportional hazards model had been used to analyze the data. 


\section{Results}

The mean $( \pm \mathrm{SD})$ of height for male patients were $64.40( \pm 4.78)$ and for female were $60.01( \pm 3.90)$. The mean $( \pm$ SD) of weight before cancer for male patients were $57.33( \pm 13.68)$ and for female were $53.63( \pm 11.60)$ and of weight after cancer for male were $50.07( \pm 11.80)$ and for female were $49.11( \pm 12.39)$. The average amount of money spent by patients was 235677.08 BDT $( \pm 329599.11$ BDT).

Among 384 cancer patients, $192(50 \%)$ patients were male and $192(50 \%)$ were female. $30.21 \%$ of patients were from age group 40-49 and $24.74 \%$ from 50-59 age group. 50 (13.02\%) of them were job holder, 177 (46.09\%) are housewife, $44(11.46 \%)$ were businessman and $36(9.38 \%)$ of them were farmer. Education level of 311 (80.99\%) individuals were below SSC, 37 (9.64\%) were HSC pass, $19(4.95 \%)$ were illiterate and $10(2.60 \%)$ individuals were graduate. $237(61.72 \%)$ of them were in stage 1 of cancer, $105(27.34 \%)$ of them were in stage $2,33(8.59 \%)$ in stage 3 and $9(2.34 \%)$ of them were in stage 4 of cancer. $65(16.93 \%)$ of them had throat cancer, 47 (12.24\%) had stomach cancer, 44 (11.46\%) had breast (Left) cancer, 42 (10.94\%) had lung cancer, 33 (8.59\%) had cervical cancer and $33(8.59 \%)$ of them had other type of cancer like anal, bone, kidney cancer etc. Total $372(96.88 \%)$ of them usually eat food at their home and rest of them at restaurant. Total $305(79.43 \%)$ of them had no relative diagnosed with cancer, $18(4.69 \%)$ had brother having cancer, $16(4.17 \%)$ had father having cancer and 13 (3.39\%) had other relatives having cancer. Total $304(79.17 \%)$ of them didn't like exercise and rest of them do like it. Among 384 cancer patients, 267 (69.53\%) of them had no other disease and 117 (30.47\%) of them had diagnosed with different disease other than cancer. Total 282 (73.44\%) of them could not bear their cost and others could.

It was also observed that $16 \%$ of cancer patients went to hospitals of Chattogram city, $14 \%$ to Sylhet and $14 \%$ to Khulna for treatment. Location of cancer by Genderdisclosed that Throat, Stomach, Lung, Colon, and Liver cancer found mostly in male patients and also Skin cancer happened to male patients more than female but the difference was high for Lung and Throat cancer but Blood cancer found in female patients more than male.On the other hand, location of cancer by division demonstrated that most throat cancer patients (18) were in Mymensignh followed by 14 in Chattogram and 14 in Rangpur and most stomach cancer patients (15) were in Sylhet. In addition, most Lung (12) and cervical (13) cancer patients found in Dhaka and Khulna respectively and Lung, Throat and Stomach cancer patients had been seen in every division. We found that $21.35 \%$ male patients preferred smoking very much and $15.63 \%$ more than average. $35.94 \%$ male patients and $36.46 \%$ female patients preferred beef/mutton less than average and $38.54 \%$ male and $41.15 \%$ female patients favored chicken moderately.

\subsection{Survival data analysis}

After one year we collected information such as: survive( yes/no), survival time (duration of disease, that is difference between death time and detecting time of cancer), weight status (increase, stable, decrease), food habits (better, normal, worse) from 4 divisions( Dhaka, Chattogram Sylhet and Mymensing). We found total 46 (22.2\%) patients died out of 207, and $31.4 \%$ patients are still survive and we did not get data from around 46.4\% patients. Among the died patients most of them are form Chattogram division (37\%) followed by Dhaka (23.9\%) and among the surviving patients most of them are from Dhaka (33.8\%) followed by Sylhet (29.2\%) and Chattogram $(23.2 \%)$.

We also observed that patients who are still survive- among them around $30 \%$ patients' weights are increased, stable $29 \%$ and decreased around $41 \%$ patients. Food habits also improved around $41 \%$, as usual11\% and getting worse around $48 \%$ patients (Table 1 ).

We found median survival time is highest in Sylhet (18 months) followed by Chattogram (15 months. However, overall survival time is 12 months in these four divisions. It is shown in confidence interval as the length of confidence interval is wider for Chattogram division and narrower in Dhaka division (Table 1). We found that more male patients (27\%) died compare to female patients (14.4\%) though median survival time of both male and female is 12 months.

\subsection{Results of Cox proportional hazard model}

In order to run the Cox-model or proportional hazard model we used gender, division and the factors of lifestyle/environmental dimension and factors of heritability dimension. Factors of lifestyle dimension and heritability dimension were selected by PCA. Initially we run the model with all 4 factors (selected from the scree plot) for lifestyle dimension and 8 factors (similarly selected from the scree plot) for heritability dimension and observed -2loglikelihood of Omnibus test. We run the model repeatedly for reducing the factors. Finally we found 4 factors from each dimension (smallest -2loglikelihood) then run the final model (Table 2). 
From the results of Cox-model it was observed that female patients are around $20 \%$ less hazard than male patients though there is no significant difference between them. We also found that factor- $1(\mathrm{p}<0.05)$, factor- 2 $(\mathrm{p}<0.05)$ and factor $3(\mathrm{p}<0.10)$ of the lifestyle dimension are significant effect on hazard of cancer and there is no factor was found significant in heritability dimension. It indicates that the variables with the highest loadings in the significant factors of the lifestyle dimension influence the hazard function of the cancer patients. In the factor analysis we observed more consumption of beverages, fast food, chips/chocolates/ice-cream, smoking and betel nut increased the hazard of cancer (Table 3).

Table 1. Median survival time of patients respect to division and gender.

\begin{tabular}{lllll}
\hline & \multirow{2}{*}{ Estimate } & \multirow{2}{*}{ Std. Error } & \multicolumn{2}{c}{ 95\% Confidence Interval } \\
\cline { 4 - 5 } & & & Lower Bound & Upper Bound \\
\hline Dhaka & 9.000 & 1.651 & 5.763 & 12.237 \\
\hline Chattogram & 15.000 & 4.939 & 5.319 & 24.681 \\
\hline Sylhet & 18.000 & 4.243 & 9.684 & 26.316 \\
\hline Mymensingh & 12.000 & 2.183 & 7.722 & 16.278 \\
\hline Overall & 12.000 & 1.121 & 9.803 & 14.197 \\
\hline Male & 12.000 & 1.789 & 8.494 & 15.506 \\
\hline Female & 12.000 & 1.587 & 8.889 & 15.111 \\
\hline Overall & 12.000 & 1.113 & 9.818 & 14.182 \\
\hline
\end{tabular}

Table 2. Results of the Cox proportional hazard model.

\begin{tabular}{lllllll}
\hline Covariates & B & SE & Wald & df & Sig. & Exp(B) \\
\hline Gender &. .199 & .377 & .279 & 1 & .597 & .820 \\
\hline Lifestyle Dimension & & & & & & \\
\hline FAC1 & -.402 & .192 & 4.383 & 1 & .036 & .669 \\
\hline FAC2 & .383 & .171 & 5.041 & 1 & .025 & $\mathbf{1 . 4 6 7}$ \\
\hline FAC3 & .270 & .148 & 3.317 & 1 & .069 & $\mathbf{1 . 3 1 0}$ \\
\hline FAC4 & -.211 & .185 & 1.309 & 1 & .253 & .809 \\
\hline Heritability Dimension & & & & & & \\
\hline FAC1 & .026 & .189 & .019 & 1 & .890 & 1.027 \\
\hline FAC2 & -.156 & .208 & .562 & 1 & .453 & .856 \\
\hline FAC3 &. .149 & .185 & .654 & 1 & .419 & .861 \\
\hline FAC4 & .220 & .148 & 2.208 & 1 & .137 & 1.246 \\
\hline
\end{tabular}

Table 3. Loadings of the variables of the selected components/factors of lifestyle dimension.

\begin{tabular}{lllll}
\hline & \multicolumn{4}{c}{ Component } \\
\cline { 2 - 5 } & $\mathbf{1}$ & $\mathbf{2}$ & $\mathbf{3}$ & $\mathbf{4}$ \\
\hline How much do you prefer Fast food & .335 & $\mathbf{. 7 0 8}$ & .011 & .208 \\
\hline How much do you prefer Vegetable & .598 & -.301 & .059 & .299 \\
\hline How much do you prefer Fish & .652 & -.192 & -.170 & .192 \\
\hline How much do you prefer beverages & .247 & $\mathbf{. 7 3 0}$ & -.118 & -.069 \\
\hline How much do you prefer Chicken & .715 & -.096 & .004 & .175 \\
\hline How much do you prefer Beef/mutton & .650 & .214 & .231 & -.321 \\
\hline How much do you prefer smoking & .248 & .213 & $\mathbf{. 6 2 8}$ & -.531 \\
\hline How much do you prefer Chips/Chocolate/ice-cream & .117 & $\mathbf{. 5 8 0}$ & -.528 & .086 \\
\hline How much do you prefer betel-nut & .093 & .133 & $\mathbf{. 6 9 7}$ & .524 \\
\hline How much do you prefer fruits & .537 & -.289 & -.244 & -.381 \\
\hline
\end{tabular}

\section{Discussion}

Cancer is the major accidental cause of dying in early stage of life especially in Bangladesh and it is becoming a major concern for health sector. To find out, how many factors are responsible for growing cancer in a body and which factors they are, many studies has been done by researchers and doctors all over the world. Though we are far away from the reasonable and flawless answer of these questions because of different cases, it has been revealed that heritability factors and lifestyle factors can be responsible for growth of cancer. To find out the 
level of lifestyle and heritability effects we have conducted a cross-sectional study on cancer patients of eight division of Bangladesh and collected information of 384 cancer patients where there are 192 male and 192 female patients, after one year we collected the survival information from the patients of 4 divisions. At first we get descriptive information of the data and then for further discovery we run PCA, survival probabilities and Cox model.

According to International Agency for Research on Cancer, the rate of occurring breast cancer (Incidence rate (IR): 46.3) was high followed by Prostate (IR: 29.3), Lung (IR: 22.5), and Colorectal cancer (IR: 19.7), among both male and female cases. On the other, among male patients lung cancer (IR: 31.5 ) found to be high followed by Prostate (IR: 29.3), Colorectal (IR: 23.6), and Stomach (IR: 15.7) and among female patients Breast cancer (IR: 46.3) was on high and then were Colorectal (IR: 16.3), Lung (IR: 14.6), and Cervix uteri (IR: 13.1) (Bray et al., 2018). From descriptive information, we found that among different cancer people throat and stomach cancer mostly and among female patients, Breast, Cervical and Ovary cancer rate is high whereas Throat and Lung cancer occurs highly among male patients. According to a study in USA for young age of people the risk of getting cancer which is obese-related was higher than older age (Sung et al., 2019). From our study we observed that people of aged 30-60 had higher chance of growing cancer than the other age group where age group 40-50 is the high-risk group. According to a study in hospitals of Dhaka city, 27\% of cancer patients were from Dhaka, followed by Cumilla (17\%) (Shahriar et al., 2011). In our study, we found that about $16 \%$ of cancer patients go to hospitals of Chattogram, followed by Sylhet (14\%). As number of patients have not fixed for each division, so it is not clear that although having high facility hospitals and trained doctor, cancer patients don't go to hospitals of Dhaka. The reasons can be that most of cancer patients are not from well-to-do family and as a result most of the time they can't afford to stay in Dhaka and maintain their treatment cost. Along with that, sometimes they prefer not to go those hospitals where costly equipments are available to avoid high treatment cost. On the other hand, patients who have enough money to treat their cancer outside Bangladesh, they don't go any hospitals as they don't trust treatment procedure and doctors of Bangladesh. From our study we found that preference of sweetened items like beverages, ice-cream, chocolate is not that much high in both male and female patients but they consumes moderately these type of foods. Another study in North-western Iran depicted that high consumption of milk of high fat, yogurt and food item with heavy cheese, deep fried meet and using same oil for 2 days increased the chance of having gastric cancer (Somi et al., 2015). Our study discovers that although in less amount but patients prefer fast food moderately and it has been seen that company or shops that make fast food or fried items use Mobil oil to make food crispier and also most of the time same oil for 2 or 3 days. A case-control study on esophageal and gastric cancers found that consumption of herby cheese and smoking was higher in cancer patients group $(\mathrm{P}<0.001)$ than the control group (Celik et al., 2015). In our study, most of the female patients don't prefer smoking at all and also for half of male patients it has been seen that smoking preference is not that much high but more than one-third of male patients prefer smoking too much while some of them may be chain-smoker. Studies found that about $10 \%$ of world's population consumed betel-nut and among them most people were from India because of its availability, low pricing etc. (Sharan and Choudhury, 2010; Sharan et al., 2012). Our study tells that about one-fifth of cancer patients prefer betel-nut strongly and rests of them chew it moderately. Another study in US found high association between colon cancer and eating main dish of beef, lamb, pork etc. every day with relative risk 2.49 comparing with eating these item once in a month among women (Willett et al., 1990) and another study in Japan stated that consumption of red meat was highly associated with the risk of having colon cancer among women (Takachi et al., 2011). Our study shows that $40 \%$ of females prefer red meat items highly which indicates slight influence of it on Cancer and same for male patients. A study on nasopharyngeal carcinoma (NPC) in China discovered that risk of having NPC was highly effected (P (trend) <0.01) by having first relative with any cancer and many members suffering from cancer (Bruner et al., 2003). In our study we detect that about $80 \%$ of cancer patients have no family history of cancer and whom having family history of cancer, most of them has first relative- father, mother, brother with cancer.

Survival data shows that around 22\% patients died in Dhaka, Chattogram, Sylhet and Mymensing divisions. Among them most people died in Chattogram followed by Dhaka. However, median survival time is higher in Chattogram and lower in Dhaka division. Considering all cancer diseases, we observed that female survival rate is higher than male patients, however, considering only stomach and colon cancer, survival rate is found higher for male than that of female (Ahammed et al., 2020). Patients who are still survive, among them most of the patients' weights are decreased as well as most of their food habits are getting worse. That is, they are suffering the diseases severely. From the Cox model it is clear that more consumption of beverages, fast food, chips/chocolates/ice-cream, smoking and betel nut increased the hazard of cancer. 


\section{Conclusions}

Although there are many studies which are similar to our study conducted in Bangladesh as well as many other countries in the world, this study can give a rough idea about the effects of lifestyle and heritability factors on cancer diseases in Bangladesh and possible idea about precautions that can be adopted in terms of different factors. It is true that the discoveries from this study may not explain or present the real scenario of different effects which are responsible for cancer but it might be help us to take further this study by studying different factors for different types of cancer individually. Taken together, the findings in this study may be able to make awareness in the society about the cancer, afterwards it may be able to reduce the cancer diseases in future in regional, national and international level. Finally, we recommend that- changing lifestyle is very essential to prevent the cancer diseases as we found lifestyle plays important role for cancer. So we should do exercise daily and avoid oily and junk food. We should take more fresh vegetables and fruits daily.

\section{Acknowledgements}

We would like to thanks the SUST Research center for funding to conduct this study. A small amount of fund has been received from Research Center SUST (Shahjalal University of Science and Technology, Sylhet-3114, Bangladesh). We also like to thanks the patients and medical stuffs for their supports.

\section{Conflict of interest}

None to declare.

\section{References}

Ahammed T, MF Akter, A Suchana, A Chowdhury, MR Shah, MS Rahman, A Akter and MO Ullah, 2020. Survival probabilities of stomach and colon cancer patients in Bangladesh. Asian J. Med. Biol. Res., 6: 123129.

Anand P, AB Kunnumakara, C Sundaram, KB Harikumar, ST Tharakan, OS Lai, B Sung, BB Aggarwal, 2008. Cancer is a Preventable Disease that Requires Major Lifestyle Changes. Pharm. Res., 25: 2097-2116.

Argos M, F Parvez, M Rahman, M Rakibuz-Zaman, A Ahmed, SK Hore, T Islam, Y Chen, BL Pierce, V Slavkovich, C Olopade, M Yunus, JA Baron, JH Graziano and H Ahsan, 2014. Arsenic and lung disease mortality in Bangladeshi adults. Epidemiol. Camb. Mass, 25: 536-543.

Ashrafunnessa, S Kahtun, TA Chowdhury, L Shamsuddin, M Islam, MS Hassan and S Ali, 2005. Human papillomavirus in cervical intraepithelial neoplasia in Bangladesh. Bangladesh J. Obstet. Gynecol., 20: 1318.

Bray F, J Ferlay, I Soerjomataram, RL Siegel, LA Torre and A Jemal, 2018. Global cancer statistics 2018: GLOBOCAN estimates of incidence and mortality worldwide for 36 cancers in 185 countries. CA. Cancer J. Clin., 68: 394-424.

Bruner DW, D Moore, A Parlanti, J Dorgan and P Engstrom, 2003. Relative risk of prostate cancer for men with affected relatives: systematic review and meta-analysis. Int. J. Cancer, 107: 797-803.

Celik S, EM Y1lmaz, F Özden, C Kotan and H Okut, 2015. The Relationship between Eating and Lifestyle Habits and Cancer in Van Lake Region: Another Endemic Region for Esophageal and Gastric Cancers. J. Cancer Epidemiol. 2015.

Coté ML, M Liu, S Bonassi, M Neri, AG Schwartz, DC Christiani, MR Spitz, JE Muscat, G Rennert, KK Aben, AS Andrew, V Bencko, H Bickeböller, P Boffetta, P Brennan, H Brenner, EJ Duell, E Fabianova, JK Field, L Foretova, S Friis, CC Harris, I Holcatova, YC Hong, D Isla, V Janout, LA Kiemeney, C Kiyohara, Q Lan, P Lazarus, J Lissowska, L Le Marchand, D Mates, K Matsuo, JI Mayordomo, JR McLaughlin, H Morgenstern, H Müeller, I Orlow, BJ Park, M Pinchev, OY Raji, HS Rennert, P Rudnai, A Seow, I Stucker, N Szeszenia-Dabrowska, M Dawn Teare, A Tjønnelan, D Ugolini, HFM van der Heijden, E Wichmann, JK Wiencke, PJ Woll, P Yang, D Zaridze, ZF Zhang, CJ Etzel and RJ Hung, 2012. Increased risk of lung cancer in individuals with a family history of the disease: a pooled analysis from the International Lung Cancer Consortium. Eur. J. Cancer Oxf. Engl. 48: 1957-1968.

Danaei G, SV Hoorn, AD Lopez, CJ Murray and M Ezzati, 2005. Causes of cancer in the world: comparative risk assessment of nine behavioural and environmental risk factors. The Lancet, 366: 1784-1793.

Fitzgerald RC, R Hardwick, D Huntsman, F Carneiro, P Guilford, V Blair, DC Chung, J Norton, K Ragunath, JH Van Krieken, S Dwerryhouse and C Caldas, 2010. Hereditary diffuse gastric cancer: updated consensus guidelines for clinical management and directions for future research. J. Med. Genet., 47: 436-444. 
GBD 2015 Disease and Injury Incidence and Prevalence Collaborators, 2016. Global, regional, and national incidence, prevalence, and years lived with disability for 310 diseases and injuries, 1990-2015: a systematic analysis for the Global Burden of Disease Study 2015. Lancet Lond. Engl., 388: 1545-1602.

GBD 2015 Mortality and Causes of Death Collaborators, 2016. Global, regional, and national life expectancy, all-cause mortality, and cause-specific mortality for 249 causes of death, 1980-2015: a systematic analysis for the Global Burden of Disease Study 2015. Lancet Lond. Engl. 388, 1459-1544.

Global Burden of Disease Cancer Collaboration, 2018. Global, Regional, and National Cancer Incidence, Mortality, Years of Life Lost, Years Lived With Disability, and Disability-Adjusted Life-Years for 29 Cancer Groups, 1990 to 2016: A Systematic Analysis for the Global Burden of Disease Study. JAMA Oncol., 4: 1553-1568.

Hasan N, MM Uddin, M Rfiquzzaman, S Chowdhury and T Wahed, 2012. Distribution of types of cancer and patterns of cancer treatment among the patients at various hospitals in Dhaka division, Bangladesh. Int. Res. J. Pharm., 3: 219-222.

Hussain SA and R Sullivan, 2013. Cancer Control in Bangladesh. Jpn. J. Clin. Oncol., 43: 1159-1169.

Hussain SMA, 2013. Comprehensive update on cancer scenario of Bangladesh. South Asian J. Cancer, 2: 279284.

Hussain SMA and M Zaman, 2008. National Cancer Control Strategy and Plan of Action 2009-15.

Kampman E, 2007. A First-Degree Relative with Colorectal Cancer: What Are We Missing? Cancer Epidemiol. Prev. Biomark., 16: 1-3.

Khatun S, SMA Hussain, F Hossain and A Choudhury, 2009. Human Papilloma Virus and Other Risk Factors of Carcinoma Cervix. Bangladesh Med. J., 38: 18-23.

McGuire S, 2016. World Cancer Report 2014. Geneva, Switzerland: World Health Organization, International Agency for Research on Cancer, WHO Press, 2015. Adv. Nutr. Bethesda Md, 7: 418-419.

McPherson K, CM Steel and JM Dixon, 2000. Breast cancer-epidemiology, risk factors, and genetics. BMJ, 321: 624-628.

Mukti RF, PD Samadder, AA Emran, F Ahmed, IB Imran, A Malaker and S Yeasmin, 2014. Score based risk assessment of lung cancer and its evaluation for Bangladeshi people. Asian Pac. J. Cancer Prev. APJCP. https://doi.org/10.7314/APJCP.2014.15.17.7021

Nelson DE, DW Jarman, J Rehm, TK Greenfield, G Rey, WC Kerr, P Miller, KD Shield, Y Ye and TS Naimi, 2013. Alcohol-Attributable Cancer Deaths and Years of Potential Life Lost in the United States. Am. J. Public Health, 103: 641-648.

Sanchez G, 2013. PLS Path Modeling with R. Trowchez Editions. Berkeley.

http://www.gastonsanchez.com/PLS Path Modeling with R.pdf

Shahriar M, RB Islam, AS Mahmood, MSA Mamun, SS Nahar, T Sadiana and S Shahid, 2011. Risk factors and trends of common cancers in Bangladesh: Outcome of hospital based case control survey conducted in Dhaka city, Bangladesh. Stamford J. Pharm. Sci., 4: 35-41.

Sharan RN and Y Choudhury, 2010. Betel nut and susceptibility to cancer. IN: Roy, D., Dorak, M.T. (Eds.), 2010. Environmental Factors, Genes, and the Development of Human Cancers. Springer-Verlag, New York. https://doi.org/10.1007/978-1-4419-6752-7.

Sharan RN, R Mehrotra, Y Choudhury and K Asotra, 2012. Association of Betel Nut with Carcinogenesis: Revisit with a Clinical Perspective. PLoS ONE 7: e42759.

Soerjomataram I, K Shield, C Marant-Micallef, J Vignat, C Hill, A Rogel, G Menvielle, L Dossus, JN Ormsby, J Rehm, L Rushton, P Vineis, M Parkin and F Bray, 2018. Cancers related to lifestyle and environmental factors in France in 2015. Eur. J. Cancer, 105: 103-113.

Somi MH, SM Mousavi, S Naghashi, E Faramarzi, MA Jafarabadi, M Ghojazade, A Majdi and SA NaseriAlavi, 2015. Is there any relationship between food habits in the last two decades and gastric cancer in NorthWestern Iran? Asian Pac. J. Cancer Prev., 16: 283-290.

Sung H, RL Siegel, PS Rosenberg and A Jemal, 2019. Emerging cancer trends among young adults in the USA: analysis of a population-based cancer registry. Lancet Public Health, 4: e137-e147.

Takachi R, Y Tsubono, K Baba, M Inoue, S Sasazuki, M Iwasaki, S Tsugane and Japan Public Health CenterBased Prospective Study Group, 2011. Red meat intake may increase the risk of colon cancer in Japanese, a population with relatively low red meat consumption. Asia Pac. J. Clin. Nutr., 20: 603-612.

Talukder MH, S Jabeen, MJ Islam and SMA Hussain, 2008. Distribution of Cancer Patients at National Institute of Cancer Research and Hospital in 2006. Bangladesh Med. J., 37: 2-5.

Uddin AFMK, ZJ Khan, J Islam and A Mahmud, 2013. Cancer care scenario in Bangladesh. South Asian J. Cancer, 2: 102-104. 
Ullah MO, A Akhter, N Sultana, M Baidya and JH Jiban, 2016. Extents of Environmental and Heritability Effects on Cancer: A Cross-Sectional Study at Sylhet City in Bangladesh. Biom. Biostat. Int. J. Volume 4.

WHO | World Cancer Report 2014 [WWW Document], n.d.. WHO. URL https://www.who.int/cancer/ publications/WRC_2014/en/ (accessed 7.8.19).

Willett WC, MJ Stampfer, GA Colditz, BA Rosner and FE Speizer, 1990. Relation of meat, fat, and fiber intake to the risk of colon cancer in a prospective study among women. N. Engl. J. Med., 323: 1664-1672.

Wolin KY, Y Yan, GA Colditz and IM Lee, 2009. Physical activity and colon cancer prevention: a metaanalysis. Br. J. Cancer, 100: 611-616.

World Health Organization, 2014. Cancer Fact Sheet.

Wu Y, D Zhang and S Kang, 2013. Physical activity and risk of breast cancer: a meta-analysis of prospective studies. Breast Cancer Res. Treat., 137: 869-882.

Zaman M and M Baki, 2009. Cancer Registry Report-National Institute of Cancer Research and Hospital 20052007. Dhaka WHO. 